\title{
Inhibition of cell proliferation and migration through nucleobase-modified polyamidoamine- mediated p53 delivery
}

This article was published in the following Dove Press journal: International Journal of Nanomedicine

\author{
Haobo Han ${ }^{1,2}$ \\ Wenqi Chen ${ }^{2}$ \\ Jiebing Yang ${ }^{2}$ \\ Xiao Liang ${ }^{2}$ \\ Yudi Wang ${ }^{2}$ \\ Quanshun $\mathrm{Li}^{2}$ \\ Yan Yang ${ }^{2}$ \\ Kun $\mathrm{Li}^{1}$
}

'School of Nursing, ${ }^{2}$ Key Laboratory for Molecular Enzymology and Engineering of Ministry of Education, School of Life Sciences, Jilin University, Changchun, People's Republic of China

\begin{abstract}
Introduction: The nucleobase 2-amino-6-chloropurine-modified polyamidoamine (APPAMAM) was used as a carrier for $p 53$ gene delivery to achieve the antitumor effects.

Methods and materials: The condensation of $p 53$ plasmid was studied through gel retardation assay, and the transfection efficiency was evaluated through the transfection assay of pEGFP-N3 and pGL-3 plasmids. Using human cervical carcinoma cell line HeLa as a model, the inhibition of cell proliferation and migration was studied through flow cytometry, wound healing and Transwell migration assays, respectively. The p53 expression level was detected through quantitative polymerase chain reaction and Western blotting analyses.

Results: The carrier could condense $p 53$ plasmid into stable nanoparticles at N/P ratios of 2.0, and higher transfection efficiency than polyamidoamine (PAMAM) could be obtained at all the N/P ratios studied. AP-PAMAM-mediated p53 delivery could achieve stronger antiproliferative effect than PAMAM/p53. The antiproliferative effect was identified to be triggered by the induction of cell apoptosis (apoptotic ratio of 26.17\%) and cell cycle arrest at $\mathrm{S}$ phase. Additionally, AP-PAMAM/p53 transfection has been found to suppress the cell migration and invasion of cancer cells. Finally, the enhanced p53 expression level could be detected after $p 53$ transfection at mRNA and protein levels.
\end{abstract}

Conclusion: The PAMAM derivative-mediated $p 53$ delivery could be a promising strategy for achieving tumor gene therapy.

Keywords: nucleobase, polyamidoamine, p53 delivery, cell proliferation, cell migration

\section{Introduction}

In cancer treatment, gene therapy transporting genes of interest and facilitating production of the desirable therapeutic proteins has shown tremendous prospects owing to its high specificity in therapeutic action of the expressed proteins. ${ }^{1}$ Thus, selecting a therapeutic gene is a key issue to be addressed in tumor gene therapy. Among the therapeutic genes, transcription factor $\mathrm{p} 53$ is one of the most important tumor suppressor genes, which mainly exerts its function through the transcriptional regulation of its downstream target genes. ${ }^{2-4}$ It has been reported that $p 53$ is the most frequently mutated gene ( $50 \%$ of human tumors), which affects single residues in the protein's core domain and thereby leads to the loss of function of binding on DNA and executing normal checkpoint. ${ }^{5,6}$ Thus, enhancing the activity of wild-type p53 or inducing the expression of wild-type p53 will be a promising approach for achieving cancer gene therapy. To date, great efforts have been contributed to improve the intracellular p53 expression level in a carrier-mediated manner ${ }^{7-14}$ and all these reports demonstrated that this strategy could achieve favorable antitumor efficacy and reduce adverse effects to normal cells or organs both at in vitro and in vivo levels. 


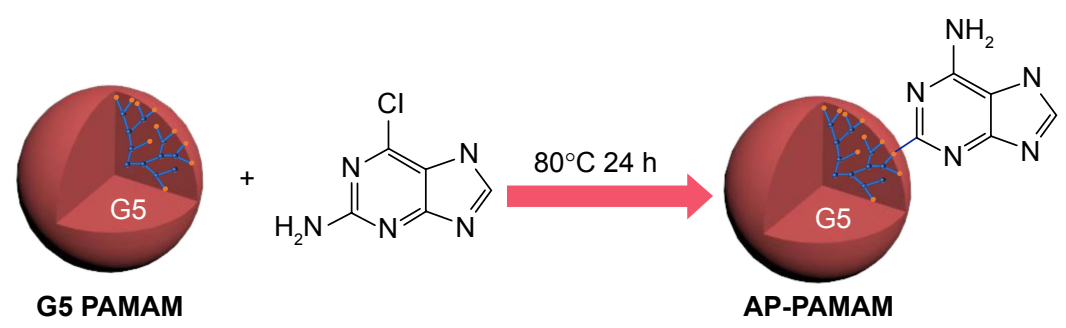

Scheme I Synthesis of AP-PAMAM through the modification of 2-amino-6-chloropurine on PAMAM dendrimer. Abbreviations: AP-PAMAM, 2-amino-6-chloropurine-modified PAMAM; PAMAM, polyamidoamine.

Another aspect to be focused on is the construction of gene delivery systems with high transfection efficiency and low cytotoxicity. In contrast to viral carriers, nonviral carriers have been considered to be an alternative in gene delivery due to their low cytotoxicity and production cost. ${ }^{15}$ As one of the synthetic cationic dendrimers, amine-terminated polyamidoamine (PAMAM) exhibited unique characteristics to be used as gene carrier, such as excellent solubility, well-defined nanostructure, low polydispersity, and high density of functional groups. ${ }^{16-18}$ Meanwhile, it possesses strong interaction with nucleic acids to obtain stable nanoparticles and its high contents of tertiary amine groups within the interior could facilitate the endosomal escape of nanoparticles in the cytosol through "proton sponge" effect. ${ }^{19-21}$ To further improve the transfection efficiency and reduce its cytotoxicity, a series of tailor-made PAMAM derivatives have been successfully constructed and applied in the gene delivery, such as the modification using amino acids, ${ }^{22,23}$ lactobionic acid,,${ }^{24}$ triazine ${ }^{25}$ or chondroitin sulfate, ${ }^{26}$ fluorination, ${ }^{27,28}$ and supramolecular approach. ${ }^{29}$ Recently, Wang et al designed a PAMAM derivative (G5-APu) through the modification of PAMAM with nucleobase analog, which has been demonstrated to possess favorable transfection efficacy and biocompatibility owing to the easier intracellular DNA unpacking. ${ }^{30}$ Thus, we anticipate that the derivative could be used as a promising carrier for achieving the efficient delivery of therapeutic genes and obtaining good antitumor efficacy.

Herein, 2-amino-6-chloropurine-modified PAMAM (AP-PAMAM) was synthesized according to the route in Scheme 1 and employed as a carrier to achieve $p 53$ gene delivery for investigating its inhibition effects on the cell proliferation, migration, and invasion, using human cervical carcinoma cell line HeLa harboring wild-type $p 53$ gene as a model.

\section{Materials and methods}

\section{Materials}

Plasmids p3XFLAG-CMV-p53 and pEGFP-N3 were stored in our laboratory, amplified in Escherichia coli DH5 $\alpha$, and purified using Axygen Plasmid Maxi kit (Hangzhou, China). The plasmid pGL3, luciferase assay, and caspase activity assay kits were purchased from Promega Corporation (Fitchburg, WI, USA). The amine-terminated PAMAM dendrimer ( $\mathrm{MW}=28,826 \mathrm{~g} / \mathrm{mol}$ ) was obtained from Chenyuan Co. (Weihai, China). 2-Amino-6-chloropurine was purchased from Aladdin (Shanghai, China). The derivative AP-PAMAM was synthesized through the conjugation of 2-amino-6-chloropurine on PAMAM according to the previous studies ${ }^{30,31}$ and structurally characterized. 3-(4,5Dimethylthiazol-2-yl)-2,5-diphenyltetrazolium bromide (MTT) was obtained from Amersco (Solon, OH, USA). Lipofectamine ${ }^{2000}$ and Lyso-Tracker Red were purchased from Thermo Fisher Scientific (Waltham, MA, USA). TRNzol Universal Reagent was purchased from TIANGEN Co. (Beijing, China). PrimeScript ${ }^{\mathrm{TM}}$ RT Reagent Kit with gDNA Eraser (Perfect Real Time) and SYBR ${ }^{\circledR}$ Premix Ex Taq $^{\mathrm{TM}}$ (Tli RNase H Plus) Kit were purchased from Takara (Dalian, China). Annexin V-fluoresceine isothiocyanate (FITC)/propidium iodide (PI) apoptosis detection kit, cell cycle detection kit, and bicinchoninic acid (BCA) protein assay kit were obtained from Bestbio (Shanghai, China). Dulbecco's Modified Eagle's Medium (DMEM) and fetal bovine serum (FBS) were obtained from Thermo Fisher Scientific. LIVE/DEAD ${ }^{\circledR}$ Viability/Cytotoxicity Kit was purchased from Thermo Fisher Scientific. The mitochondrial membrane potential assay kit with JC-1 was obtained from Beyotime Institute of Biotechnology(Jiangsu, China). Polyvinylidene fluoride (PVDF) membrane was purchased from EMD Millipore (Billerica, MA, USA). The antibodies against procaspase- $3,-8$, and -9, p53 and $\beta$-actin, horseradish peroxidase (HRP)-labeled goat antirabbit IgG, and HRPlabeled goat anti-mouse IgG were purchased from Abcam (Shanghai, China). All other reagents were of the highest grade commercially available and used as received.

\section{In vitro transfection efficiency assay}

The HeLa cells were obtained from the Shanghai Institute of Cell Bank (Shanghai, China) and seeded into six-well plates 
at a density of $2.0 \times 10^{5}$ cells/well $24 \mathrm{~h}$ prior to the experiment. Various nanoparticles containing DNA ( $2 \mu \mathrm{g}$ pEGFP-N3 or pGL-3 plasmid for each well) at different N/P ratios were added into each well harboring $2 \mathrm{~mL}$ of serum-free DMEM. The cells were then incubated for $6 \mathrm{~h}$, and the medium was replaced by $10 \%$ fresh FBS-containing DMEM. After the transfection for $48 \mathrm{~h}$, the expressed GFP were observed through Olympus IX73P1F fluorescence microscopy (Olympus Corporation, Tokyo, Japan). For quantitative assay, the cells were harvested and analyzed via BD fluorescence activated cell sorting (FACS) caliber (BD Biosciences, San Jose, CA, USA). The activity of luciferase produced by cells transfected with pGL-3 plasmid was evaluated according to manufacturer's instructions. The luminescence of luciferase activity was determined with a TECAN Infinite F200 Pro plate reader (Tecan, Mannedorf, Switzerland).

\section{DNA condensation ability assay}

The DNA condensation ability of AP-PAMAM was evaluated by agarose gel retardation assay. The nanoparticles were prepared by gently mixing the $\mathrm{p} 53$ plasmid and carrier at different N/P ratios and then incubated at room temperature for $30 \mathrm{~min}$. Then, the nanocomplex solution was subjected to $1 \%$ agarose gel electrophoresis in Tris-acetate-EDTA buffer solution (120 V, $20 \mathrm{~min})$ and the DNA bands were detected using a Tanon 1600 gel-imaging system. The hydrodynamic diameter and zeta potential of nanoparticles were measured by Malvern Nano ZS90 Zetasizer (Malvern Instruments, Malvern, UK).

\section{In vitro cytotoxicity and antiproliferation analysis}

The in vitro cytotoxicity of AP-PAMAM and PAMAM and the inhibition of cell proliferation were evaluated by MTT method on HeLa cells. Briefly, cells (8,000 cells/well) were seeded into 96-well plates and incubated in DEME containing $10 \% \mathrm{FBS}$ at $37^{\circ} \mathrm{C}$ overnight. Various concentrations of polymers or nanoparticles containing p53 plasmid $(2.5 \mu \mathrm{g} / \mathrm{mL}$ DNA) were then added into wells containing $200 \mu \mathrm{L}$ of serum-free DMEM. For in vitro cytotoxicity assay, $20 \mu \mathrm{L}$ of MTT solution ( $5 \mathrm{mg} / \mathrm{mL}$ ) was added into each well after $24 \mathrm{~h}$ and incubated at $37^{\circ} \mathrm{C}$ for additional $4 \mathrm{~h}$. For antiproliferation analysis, the nanoparticles containing medium were replaced by fresh DMEM after $6 \mathrm{~h}$, and following additional $48 \mathrm{~h}$ incubation, the systems were treated with MTT solution as described earlier. Finally, the formazan crystal was dissolved in dimethyl sulfoxide (DMSO) and the absorbance at $492 \mathrm{~nm}$ was detected using a GF-M3000 microplate reader (CAIHONG, Shandong, China). The cell viability and the inhibition of cell proliferation were calculated as the ratio of the absorbance values of treated and untreated cells.

\section{Live/dead staining}

The cells $\left(2.5 \times 10^{5}\right.$ cells/well $)$ were planted into six-well plates and incubated at $37^{\circ} \mathrm{C}$ overnight. The cells were treated with AP-PAMAM/p53 and PAMAM/p53 nanoparticles $(2.5 \mu \mathrm{g} / \mathrm{mL}$ p53 plasmid, N/P ratio of 30) in serum-free medium for $6 \mathrm{~h}$ and incubated in substituted DMEM containing $10 \%$ FBS for another $48 \mathrm{~h}$. After washing with $1 \mathrm{~mL}$ PBS twice, $200 \mu \mathrm{L}$ of the combined live/dead cell staining solution $(2 \mathrm{mM}$ calcein AM and $4 \mathrm{mM}$ EthD-1) was added to each well and incubated with cells at room temperature for $30 \mathrm{~min}$. Images were obtained using Olympus IX73P1F fluorescence microscopy.

\section{Inhibition of colony formation assay}

The cells were incubated into six-well plates with a density of $2.5 \times 10^{5}$ cells/well overnight and then transfected with different nanoparticles (N/P ratio of 30 ) for $6 \mathrm{~h}$ in serum-free medium. After the culture in 10\% FBS-containing DMEM for $48 \mathrm{~h}$, the treated cells were digested using $0.25 \%$ trypsin and, then, were re-seeded into individual wells of six-well plates with a density of $2.0 \times 10^{4}$ cells for a week. Prior to the staining with $0.2 \%$ crystal violet solution, the cells were fixed with $70 \%$ cold ethanol at $4^{\circ} \mathrm{C}$ for $20 \mathrm{~min}$. Finally, the colony formation was observed through Olympus IX73P1F fluorescence microscopy.

\section{Induction of cell apoptosis assay}

The HeLa cells $\left(2.5 \times 10^{5}\right.$ cells/well $)$ were plated in six-well plates for the apoptosis assay. The nanoparticles (N/P ratio of $30,2.5 \mu \mathrm{g} / \mathrm{mL}$ p53 plasmid) were added into wells with free medium. After the incubation for $6 \mathrm{~h}$, the cell culture was changed to $10 \%$ FBS-containing DMEM. The cells were trypsinized and harvested after $48 \mathrm{~h}$ incubation and treated with Annexin V-FITC/PI apoptosis detection kit based on the manufacturer's protocol. Afterwards, the cells were detected by BD FACS caliber, using the BD CellQuest Pro software for analysis.

\section{Induction of cell cycle arrest assay}

The cell culture and p53 plasmid transfection were conducted as described in the cell apoptosis assay. For cell cycle arrest assay, the treated cells were harvested, washed with PBS, and fixed with precooled $70 \%$ ethanol in the dark at $-20^{\circ} \mathrm{C}$ for $1 \mathrm{~h}$. Then, the fixed cells were washed with PBS and applied in the RNase I treatment at $37^{\circ} \mathrm{C}$ for $30 \mathrm{~min}$. Finally, the cells were stained with PI staining at $4{ }^{\circ} \mathrm{C}$ for additional $30 \mathrm{~min}$ and then measured through BD FACS caliber. 


\section{Western blotting analysis}

The treatment of HeLa cells was performed as described in the cell apoptosis assay. The cultured cells were lysed in the radioimmunoprecipitation assay buffer supplemented with $1 \mathrm{mM}$ phenylmethanesulfonyl fluoride on ice for $1 \mathrm{~h}$, and total protein was extracted and quantified by BCA method. Equal amounts of protein were employed in 12\% SDS-PAGE followed by transferring to PVDF membrane. After blocking with $5 \%$ skim milk power in $0.1 \%$ Tween in phosphate buffered saline (PBST) at room temperature for $2 \mathrm{~h}$, the membrane was incubated with primary antibody at $4^{\circ} \mathrm{C}$ overnight and subsequently washed with PBST three times for $15 \mathrm{~min}$ at room temperature. The membranes were then incubated with appropriate HRP-labeled secondary antibody at a dilution of 1:5,000 for $1 \mathrm{~h}$. Subsequently, the membrane was washed with PBST and detected in Tanon 2500 chemiluminescence imaging system (Tanon, Shanghai, China).

\section{Caspase- $3,-8$, and -9 activity assay}

The activities of caspase- $3,-8$, and -9 in the transfected HeLa cells were measured using the corresponding assay kits. The cell culture and nanoparticles' treatment were performed as described in the cell apoptosis assay. The 20,000 treated cells per well were harvested and suspended with cell lysis buffer. The cell lysates were incubated with their individual substrates in the dark at room temperature for $2 \mathrm{~h}$. The luminescence signal of caspase activity was detected with TECAN Infinite F200 Pro plate reader.

\section{Mitochondrial membrane potential detection}

The mitochondrial membrane potential was measured using the lipophilic JC-1 dye. Briefly, HeLa cells were seeded into the six-well plates at a density of $2.5 \times 10^{5}$ cells/well and cultured overnight. After $p 53$ transfection for $48 \mathrm{~h}$, the cells were stained with JC- 1 dye at $37^{\circ} \mathrm{C}$ for $30 \mathrm{~min}$ and rinsed with PBS. Finally, the stained cells were observed with Olympus IX73P1F fluorescence microscopy.

\section{Classical real-time polymerase chain reaction (RT-PCR) and quantitative polymerase chain reaction ( $\mathrm{PPCR}$ )}

HeLa cells seeded into six-well plates with $2.5 \times 10^{5}$ cells were transfected with different nanoparticles (N/P ratio of $30,2.5 \mu \mathrm{g} / \mathrm{mL}$ plasmid) as described earlier. After the transfection for $48 \mathrm{~h}$, total RNAs were extracted according to the manufacturer's recommended protocols with TRIzol Reagent. To generate cDNA, a total of $1 \mu \mathrm{g}$ RNA was used for reverse transcription using PrimeScript RT Reagent Kit. For classical RT-PCR amplification, the condition was set up as follows: one cycle at $94^{\circ} \mathrm{C}$ for $2 \mathrm{~min}$, followed by 30 cycles at $94^{\circ} \mathrm{C}$ for $30 \mathrm{~s}, 55^{\circ} \mathrm{C}$ for $30 \mathrm{~s}$, and $72^{\circ} \mathrm{C}$ for $1 \mathrm{~min}$. The PCR products were detected by $2 \%$ agarose gel electrophoresis. RT-PCR was performed in Applied Biosystems 7500 RT-PCR System (Thermo Fisher Scientific) programmed for 40 cycles $\left(95^{\circ} \mathrm{C}\right.$ for $5 \mathrm{~s}, 60^{\circ} \mathrm{C}$ for $\left.34 \mathrm{~s}\right)$ using the SYBR Premix Ex Taq (Tli RNase H Plus) Kit. The $\beta$-actin gene was used as an endogenous control. The data of RT-PCR were analyzed with $2^{-\triangle \triangle C T}$ method. The primers were as follows: p53 forward: 5'-GGCTCTGACTGTACCACCATCCA-3'; reverse: $5^{\prime}$-GGCACAAACACGCACCTCAAAG-3'; $\beta$-actin forward: 5'-TCTGGCACCACACCTTCTACAATG-3'; reverse: 5'-GGATAGCACAGCCTGGATAGCAA-3'.

\section{Wound healing assay}

Briefly, monolayer cells with $95 \%$ confluence were subjected to produce wounds by scratching the surface of each well in a six-well plate with a $200 \mu \mathrm{L}$ pipette tip. The cells were then rinsed with PBS three times and transfected with different nanoparticles containing p 53 plasmid (N/P ratio $30,2.5 \mu \mathrm{g} / \mathrm{mL}$ p53 plasmid) in medium without serum. After $6 \mathrm{~h}$, the medium was changed to the $10 \%$ FBS-containing DMEM and the cells were cultured for additional $48 \mathrm{~h}$. Images of the initial wound and the movement of cells into the scratched area were captured using Olympus IX73P1F fluorescence microscopy.

\section{Transwell migration assay}

The cell invasion assay was performed using a 24-well Transwell chamber. HeLa cells after transfection were seeded at a density of $2 \times 10^{4}$ cells into the upper chamber (pore size, $8 \mu \mathrm{m}$ ), and lower chamber was filled with $700 \mu \mathrm{L}$ of DEME containing 10\% FBS. Following incubation at $37^{\circ} \mathrm{C}$ for $24 \mathrm{~h}$, cells on the upper side of the membrane were removed using clean swabs and cells on the lower side were fixed with $70 \%$ cold ethanol and then stained with $0.2 \%$ crystal violet solution. After washing with PBS three times, invaded cells were observed using the Olympus IX73P1F fluorescence microscopy.

\section{Statistical analysis}

All the data were presented as mean value $\pm \mathrm{SD}$, and statistically significant differences between different experimental groups and control group were examined using oneway analysis of variance (ANOVA) with GraphPad Prism 6 complemented with Student's $t$-test (ns, not significant; $* P<0.05 ; * * P<0.01)$. 


\section{Results and discussion}

According to the previous report, ${ }^{30}$ the carrier AP-PAMAM was constructed through the modification of PAMAM with 2-amino-6-chloropurine via a facile method and structurally characterized. Then, the in vitro transfection efficiency of AP-PAMAM was evaluated using the transfection of pEGFP-N3 and pGL-3 as models. As shown in Figure S1, both AP-PAMAM/pEGFP-N3 and PAMAM/pEGFP-N3 nanoparticles exhibited improved transfection efficiency with the increasing N/P ratio. Remarkably, more GFPexpressing cells could be observed in the AP-PAMAM transfection group at all the N/P ratios studied, indicating its higher transfection efficiency. Similarly, higher transfection efficiency was also observed for the derivative APPAMAM using pGL-3 transfection as a model (Figure S2). The transfection efficiency has been considered to be associated with several factors such as cellular uptake, internationalization mechanism, characteristics of the formulations, and cell lines. Then, we investigated the cellular uptake and intracellular distribution of FITC-labeled carrier through flow cytometry and confocal laser scanning microscope, respectively. As shown in Figures S3 and S4, though the endocytosis ability of AP-PAMAM has been decreased, stronger green fluorescence in the cytosol could be clearly observed for the carrier AP-PAMAM implying the enhanced endosomal escape. Thus, the enhanced transfection of AP-PAMAM could be probably caused by the easier intracellular DNA unpacking, which was consistent with the previous report. ${ }^{30,31}$

Then, the derivative AP-PAMAM was employed as a carrier for $p 53$ delivery. As the ability to condense the pDNA to form stable nanoparticles was essential for successful gene delivery, gel retardation assay was performed to evaluate the binding and condensation ability of AP-PAMAM with plasmid p3XFLAG-CMV-p53. As shown in Figure 1, both
PAMAM and AP-PAMAM exhibited favorable DNA-binding ability and could condense pDNA into stable nanoparticles when the N/P ratios were $>1.0$ and 2.0, respectively. Though AP-PAMAM showed a decreased pDNA binding and condensation ability compared to PAMAM mainly owing to the decreased positive charge after modification, AP-PAMAM still possessed excellent pDNA condensation ability to further facilitate the internalization and intracellular traffic of p53 plasmid. Before the antiproliferative analysis of APPAMAM/p53 transfection, the cytotoxicity of AP-PAMAM was evaluated in HeLa cells through MTT assay. As shown in Figure 2A, the derivative AP-PAMAM exhibited better biocompatibility than PAMAM in the concentration of $5-150 \mu \mathrm{g} / \mathrm{mL}$. At a concentration of $150 \mu \mathrm{g} / \mathrm{mL}$, up to $84.9 \%$ of cell viability could be obtained for AP-PAMAM while only $61.9 \%$ of corresponding value was observed for the carrier PAMAM. The reduced cell cytotoxicity of synthesized carrier after modification was mainly attributed to the decreased positive charge density on the carrier surface and the introduction of nucleobase with intrinsic low cytotoxicity, which has been demonstrated in Figure S5. To investigate the therapeutic effect of tumor suppressor p 53 gene in cancer cells, the cell viability after $\mathrm{p} 53$ transfection was determined using HeLa cells as model. As shown in Figure 2B, APPAMAM-mediated p53 delivery could obviously inhibit the cell proliferation at all the N/P ratios studied, much stronger than the carrier PAMAM. Meanwhile, the p53 transfection using AP-PAMAM as carrier showed a high dependence on the N/P ratio when it was $<30$, with $20.9 \%$ of inhibition of cell proliferation obtained at an N/P ratio of 30 . However, when the N/P ratio increased to 40 or 50 , there were no significant enhancements in the inhibition of cell proliferation. Since the superior inhibition of cell proliferation could be achieved at an N/P ratio of 30 , the value was employed as the transfection ratio in the following research. Though the commercial

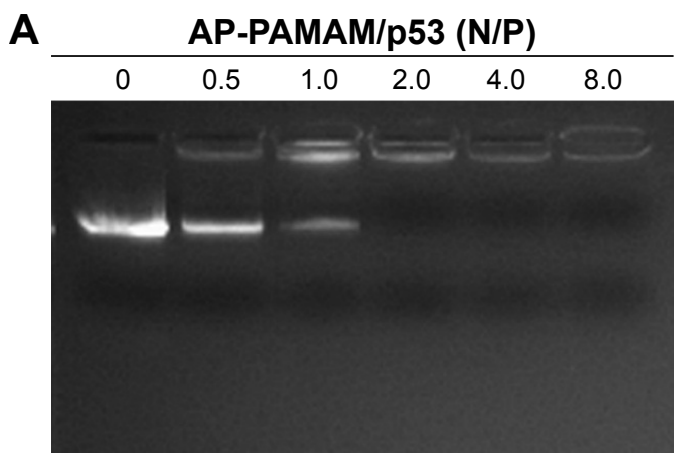

B

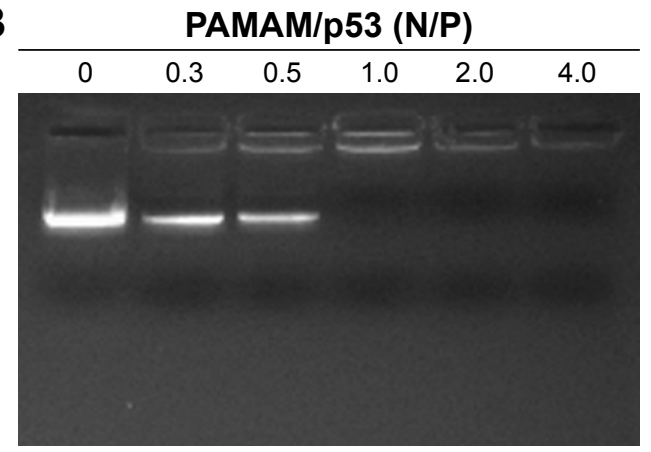

Figure I Gel retardation assay of AP-PAMAM (A) and PAMAM (B) with the plasmid p3XFLAG-CMV-p53. Abbreviations: AP-PAMAM, 2-amino-6-chloropurine-modified PAMAM; PAMAM, polyamidoamine. 

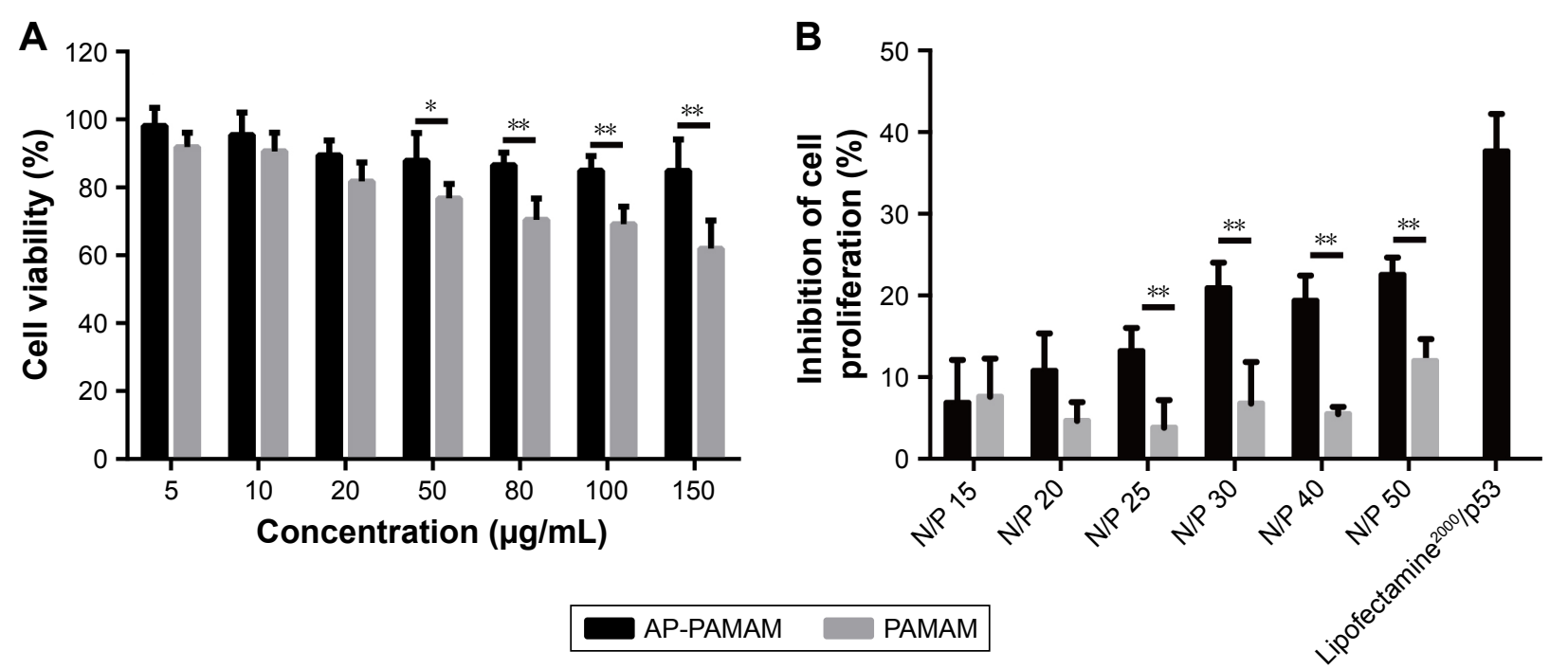

Figure 2 Cytotoxicity analysis of derivative AP-PAMAM at various concentrations in HeLa cells $(\mathbf{A})$ and inhibition of cell proliferation after the p53 transfection mediated by different carriers (B).

Notes: The data were presented as the mean \pm SD of triplicate experiments ${ }^{*} P<0.05 ; * * P<0.01$.

Abbreviations: AP-PAMAM, 2-amino-6-chloropurine-modified PAMAM; PAMAM, polyamidoamine.

transfection agent lipofectamine ${ }^{2000}$-mediated $p 53$ delivery could achieve a relatively higher antiproliferative effect, its intrinsic high cytotoxicity made it not suitable for obtaining ideal transfection, especially at an in vivo level. At an N/P ratio of 30, the hydrodynamic size and zeta potential of APPAMAM/p53 nanoparticle were measured to be $108.9 \mathrm{~nm}$ and $+17.5 \mathrm{mV}$, respectively (Table S1), which were suitable for the cellular uptake of nanoparticle and obtaining ideal transfection efficiency. ${ }^{9,27}$

Furthermore, live/dead assay was conducted after $p 53$ transfection to obtain a direct evidence for the inhibition of cell proliferation (Figure 3 ). The viable cells were labeled to green owing to the intracellular enzymatic hydrolysis of calcein AM while dead cells were observed to emit red fluorescence due to the intercalation of ethidium homodimer to DNA. ${ }^{32}$ Clearly, in contrast to control, stronger red fluorescence could be detected in AP-PAMAM/p53 group implying the presence of more apoptotic cells. Meanwhile, the inhibition ability of cell proliferation was also higher than PAMAM/p53 group. As the majority of cells treated with AP-PAMAM were dyed to green, the inhibition of cell proliferation was mainly caused by the induction of

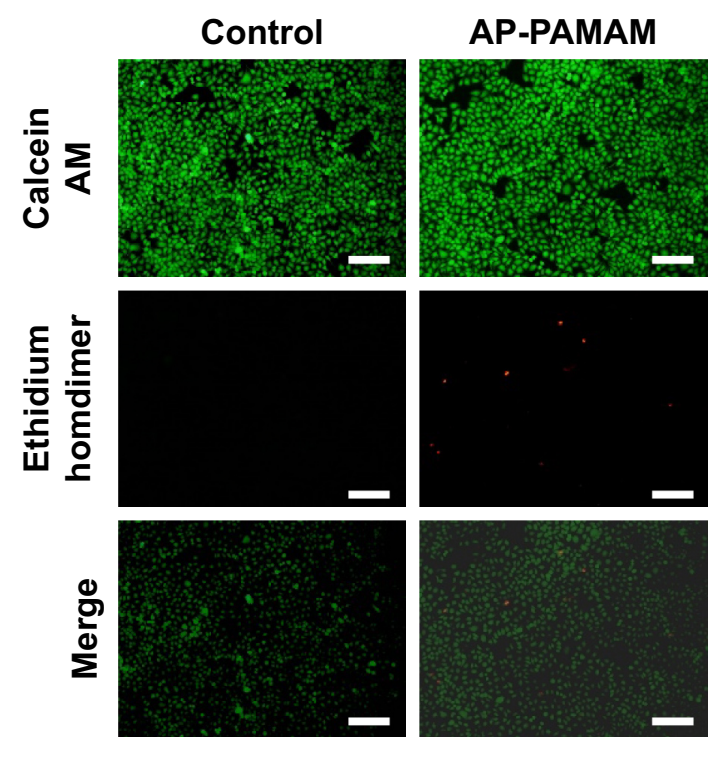

\section{PAMAM/p53}
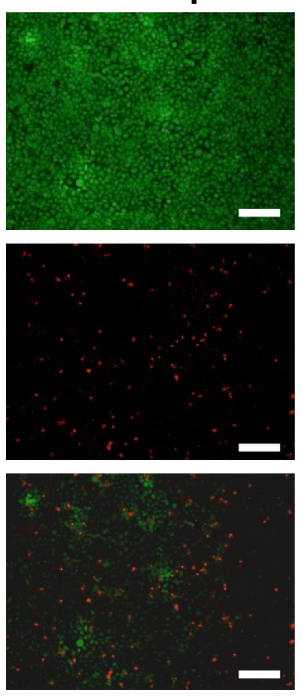

AP-PAMAM/p53
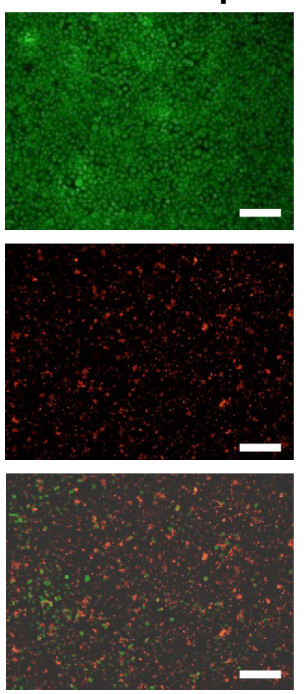

Figure 3 Live/dead assays of HeLa cells after p53 transfection mediated by different carriers.

Abbreviations: AP-PAMAM, 2-amino-6-chloropurine-modified PAMAM; PAMAM, polyamidoamine. 
cell apoptosis by $p 53$ gene. In addition, PAMAM- or APPAMAM-mediated p53 delivery could inhibit the formation of cell colony (Figure S6). All these results demonstrated that AP-PAMAM could efficiently deliver p53 plasmid into the tumor cells and then realize the expression of p53 protein and its antiproliferative function.

To further investigate the mechanism of the proliferation inhibition on cancer cells, the effect of nanoparticles on apoptosis was conducted by Annexin V-FITC/PI double staining followed by flow cytometer analysis (Figure 4). Compared with control group, apoptosis was barely observed in HeLa cells exposed to the carrier AP-PAMAM. Notably, both PAMAM/p53 and AP-PAMAM/p53 groups could induce the cell apoptosis and AP-PAMAM/p53 transfection could trigger the stronger cell apoptosis with apoptotic ratio of $26.17 \%$ than PAMAM/p53 (5.57\%). These results were consistent with MTT assay, implying that the carrier AP-PAMAM could efficiently delivery p53 plasmid and thus realize its intracellular apoptosis-dependent function.

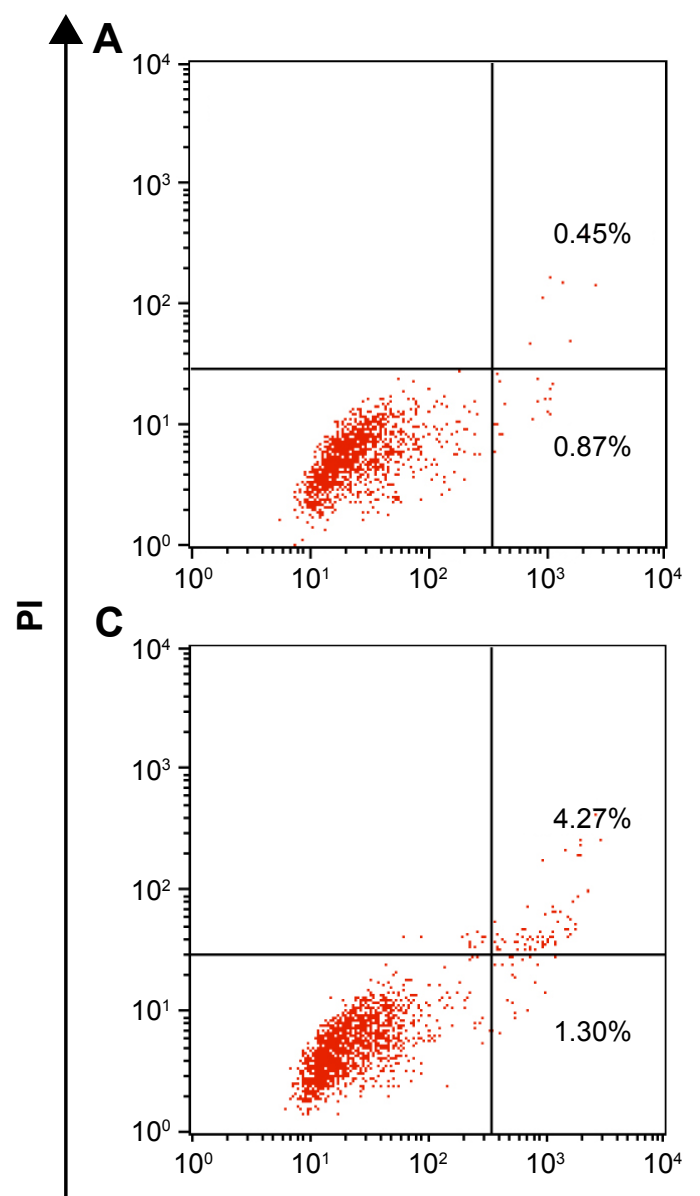

Since the $p 53$ transfection mediated by PAMAM or AP-PAMAM could achieve the inhibition of cell proliferation, then the $\mathrm{p} 53$ level was investigated both at mRNA and protein levels to check whether the antiproliferative effect was attributed to the improved p53 expression level. As shown in Figure 5A, the expression of endogenous wild-type $p 53$ gene in HeLa cells was relatively low and the band intensity of p53 (153 bp) has been observed to be obviously enhanced after carrier-mediated p53 delivery. Through qPCR analysis, the relative $p 53$ mRNA has been increased by 19.2 and 33.6 times using PAMAM and AP-PAMAM as carriers, respectively (Figure 5B). At protein expression level, p53 level was also detected to be improved after $p 53$ transfection (Figure 6). Thus, exogenous $p 53$ gene delivery in a carrier-mediated manner could increase the intracellular expression level in tumor cells with wild-type p53 gene, thereby executing its function of p53 protein.

To verify the apoptotic pathway induced by APPAMAM-mediated p53 delivery, we analyzed the expression levels of apoptosis-associated proteins

B

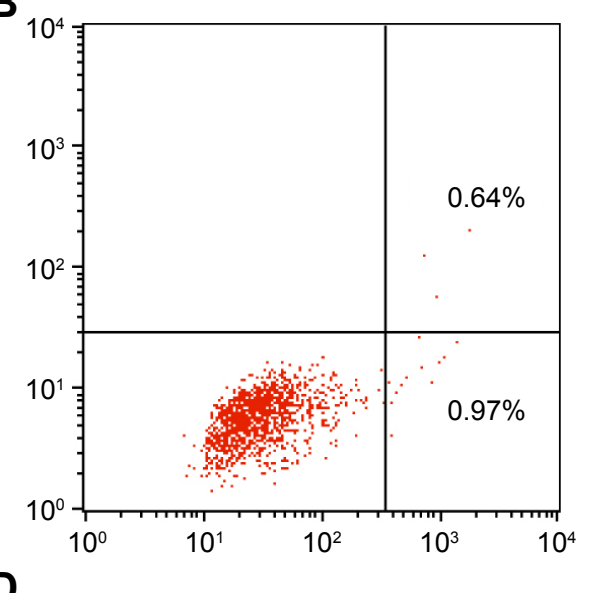

D

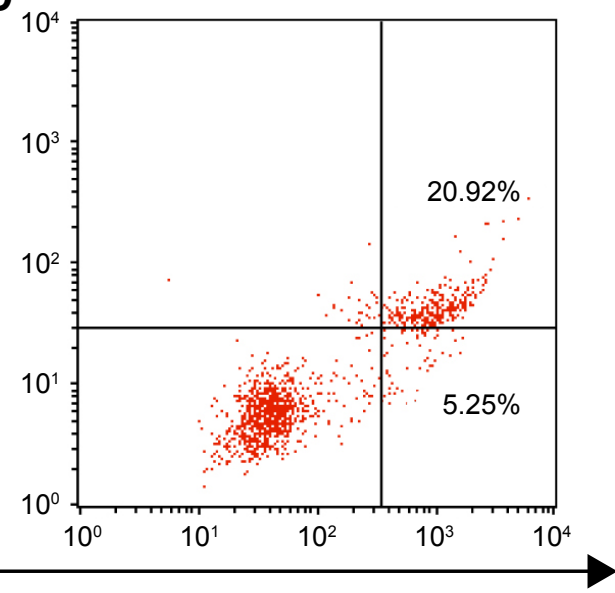

Annexin V

Figure 4 Induction of cell apoptosis through the carriers mediated p53 delivery: (A) control; (B) AP-PAMAM; (C) PAMAM/p53; and (D) AP-PAMAM/p53. Note: The cell apoptosis was detected through Annexin V-FITC/PI double staining followed by flow cytometer analysis.

Abbreviations: AP-PAMAM, 2-amino-6-chloropurine-modified PAMAM; FITC, fluoresceine isothiocyanate; PI, propidium iodide; PAMAM, polyamidoamine. 
A

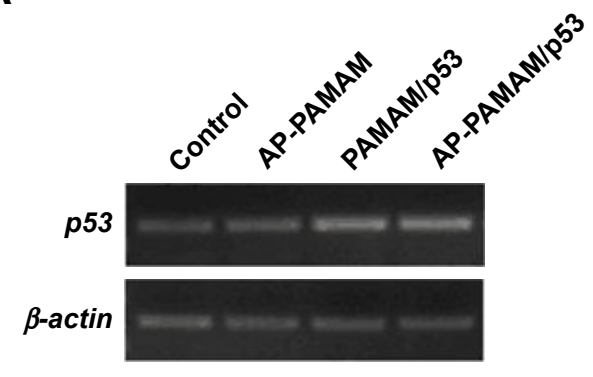

B

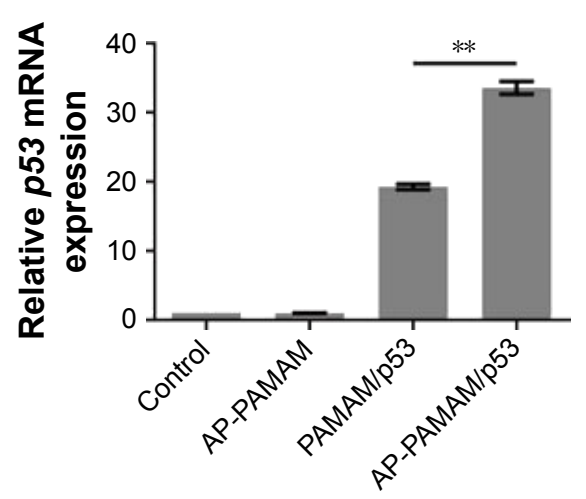

Figure 5 RT-PCR (A) and qPCR (B) analyses of p53 mRNA level after p53 transfection mediated by different carriers.

Note: $* * P<0.01$.

Abbreviations: AP-PAMAM, 2-amino-6-chloropurine-modified PAMAM; PAMAM, polyamidoamine; RT-PCR, real-time polymerase chain reaction; qPCR, quantitative polymerase chain reaction.

(procaspase-3, -8, and -9) through Western blotting. As shown in Figure 6, AP-PAMAM did not change the expression level of procaspase-3, while both the PAMAM/p53 and AP-PAMAM/ p53 treatments could sharply decrease the procaspase- 3 expression. The cleavage of procaspase- 3 would achieve the activation of caspase- 3 and then trigger the apoptotic program, as caspase- 3 has been widely accepted as the central regulator of apoptosis. ${ }^{33}$ The procaspase- 9 expression level has been observed to be decreased after $p 53$ transfection, indicating the activation of caspase- 9 and the involvement of mitochondria-mediated apoptotic pathway in the cell apoptosis. Meanwhile, the activities of caspase-3 and -9 after $p 53$ transfection have been observed to be enhanced through the corresponding activity analysis kits using the luminescence signal measurement (Figure S7), which was consistent with Western blotting analysis. Through there were no significant differences in the expression level of procaspase- 8 , the caspase- 8 activity has been detected to be enhanced after $p 53$ delivery. This phenomenon was probably

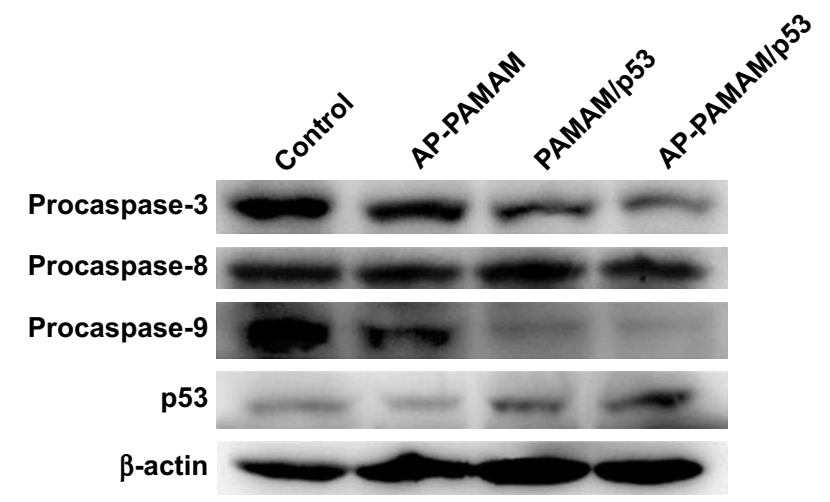

Figure 6 Western blotting analysis for the expression levels of p53 and apoptosisassociated proteins.

Abbreviations: AP-PAMAM, 2-amino-6-chloropurine-modified PAMAM; PAMAM, polyamidoamine. caused by the detection of procaspase- 8 , not caspase- 8 in Western blotting analysis, which could not show the cleaved caspase- 8 bands. According to the activity analysis of caspase- 8 , we inferred that the $p 53$ delivery might trigger the activation of caspase- 8 and execute the cell apoptosis in death receptor-mediated pathway. Additionally, the mitochondrial membrane potential was measured using JC-1 after $p 53$ transfection (Figure 7). After $p 53$ transfection using PAMAM and AP-PAMAM as carriers, red fluorescence was decreased and green fluorescence from the monomeric state of JC-1 was obviously increased, implying the decrease of mitochondrial membrane potential during the apoptotic process. These results indicated that the AP-PAMAM-mediated p53 transfection could activate the mitochondria-dependent pathway for triggering the cell apoptosis.

To further identify whether the antiproliferative effect induced by $p 53$ transfection was associated with the cell cycle arrest, the cells after $p 53$ transfection were stained by PI and subjected to flow cytometry. As shown in Figure 8, compared to control (S phase of 33.8\%), PAMAM/p53 and AP-PAMAM/p53 transfections could improve the proportion of S phase with values 39.6 and $42.1 \%$, respectively. These results were consistent with the fact that tumor suppressor p53 gene could induce a block of cell cycle at G1/S phase. ${ }^{9}$ Thus, it could be concluded that the p53-triggered inhibition of cell proliferation could be attributed to not only the cell apoptosis but also the induction of cell cycle arrest.

Finally, the antimigration effect after $p 53$ transfection was evaluated using wound healing and Transwell migration assays. As shown in Figure 9, compared to the control group, cells transfected with p53 plasmid migrated more slowly to the scratch wounds, suggesting the antimigration function of $p 53$ gene. Moreover, AP-PAMAM/p53 

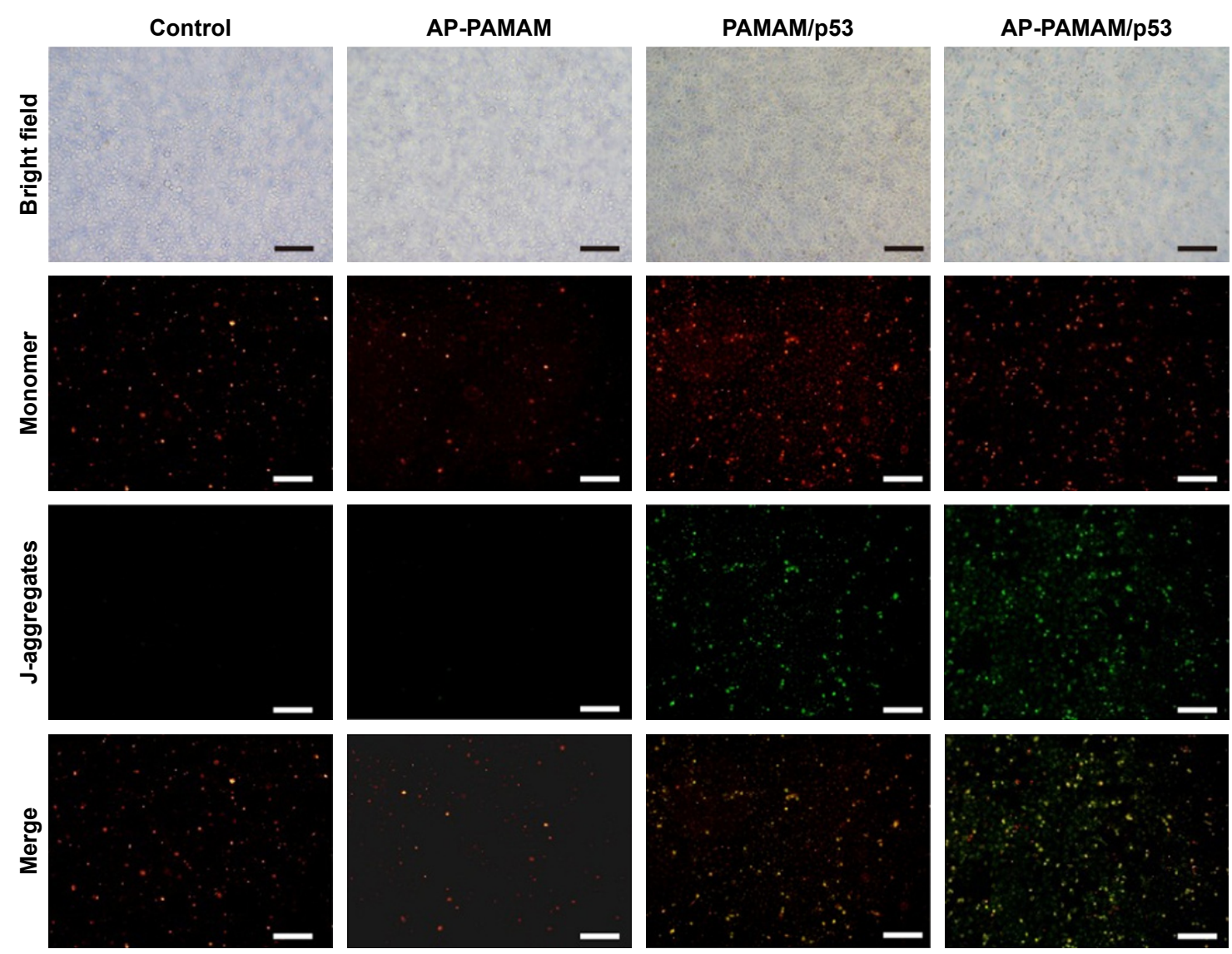

Figure 7 The mitochondrial membrane potential analysis of HeLa cells after p53 transfection mediated by different carriers. Abbreviations: AP-PAMAM, 2-amino-6-chloropurine-modified PAMAM; PAMAM, polyamidoamine.

A a

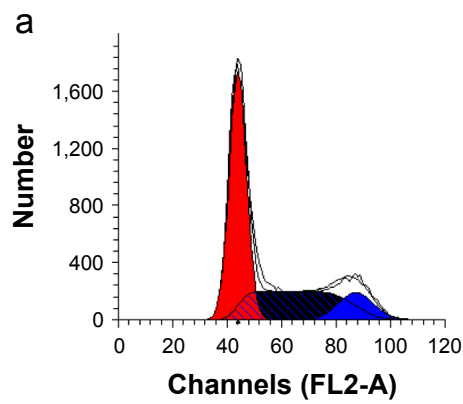

C

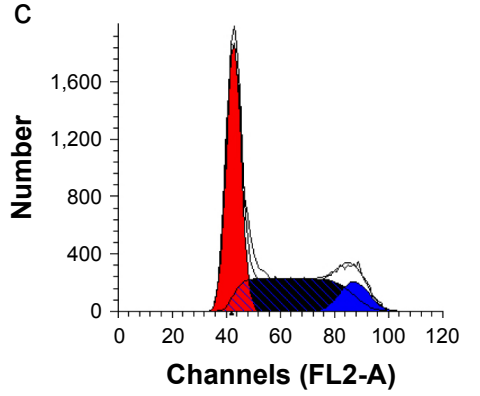

b

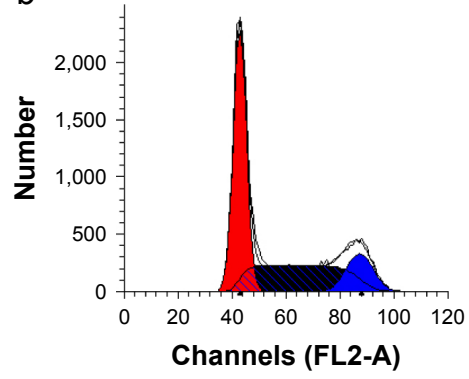

d

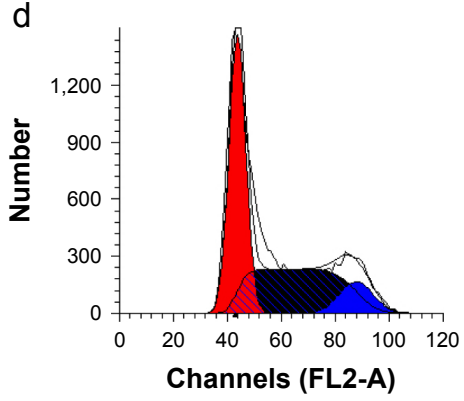

B

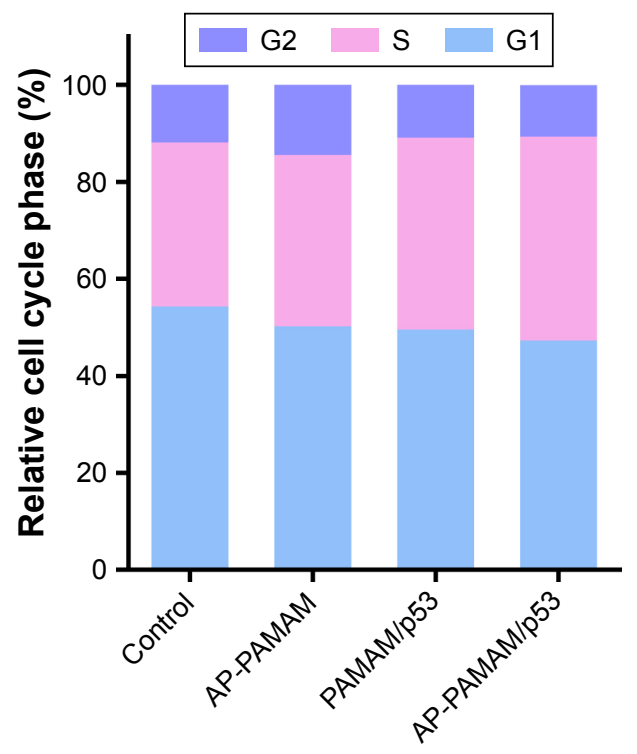

Figure 8 Cell cycle analysis through PI staining and following flow cytometry for the cells after different carriers mediated $p 53$ transfection (A) and the quantitative measurement of cell cycle phase (B). (a) control; (b) AP-PAMAM; (c) PAMAM/p53; and (d) AP-PAMAM/p53.

Abbreviations: AP-PAMAM, 2-amino-6-chloropurine-modified PAMAM; PI, propidium iodide; PAMAM, polyamidoamine. 
A
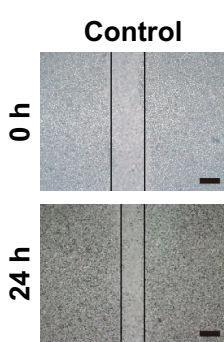

$\underset{\mathbf{\infty}}{\mathbf{\infty}} \mid$
AP-PAMAM
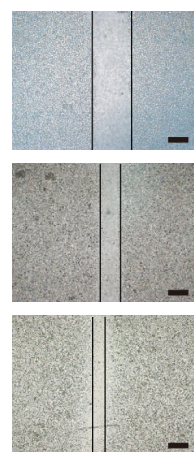

PAMAM/p53 AP-PAMAM/p53
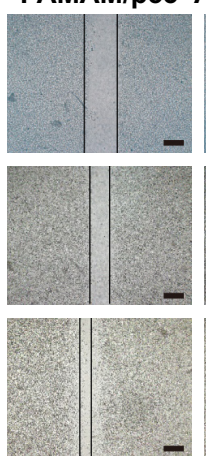
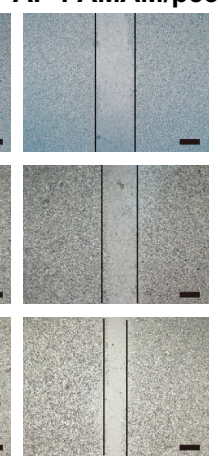

B

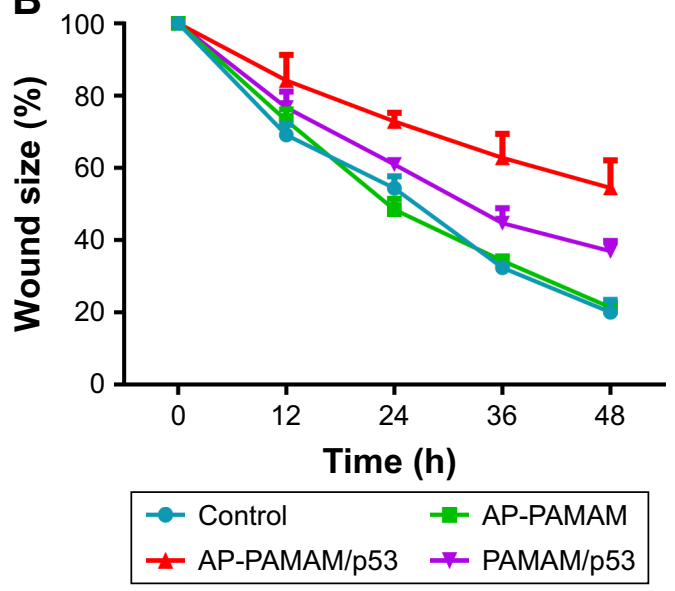

Figure 9 Wound healing assay of HeLa cells after p53 transfection for different time (A) and the quantitative analysis of wound size (B). Note: The scale bar is $400 \mu \mathrm{m}$.

Abbreviations: AP-PAMAM, 2-amino-6-chloropurine-modified PAMAM; PAMAM, polyamidoamine.

transfection exhibited a superior inhibition of migration than PAMAM-mediated $p 53$ delivery, due to the enhanced gene transfection ability of AP-PAMAM. Furthermore, Transwell migration assay showed that the invasion ability of HeLa cells has been obviously decreased after $p 53$ transfection and greater invasive inhibition could be detected in AP-PAMAM/p53 transfection group than in PAMAM/p53 transfection (Figure 10). In summary, the synthesized carrier AP-PAMAM could efficiently deliver therapeutic gene p53 into cancer cells to achieve the goal of inhibiting the cell migration.

\section{Conclusion}

The derivative AP-PAMAM could efficiently achieve the delivery of $p 53$ gene into HeLa cells. Through $p 53$ gene transfection, the proliferation, migration, and invasion of tumor cells could be successfully inhibited. Thus, the nucleobasemodified dendrimer could potentially be employed as a
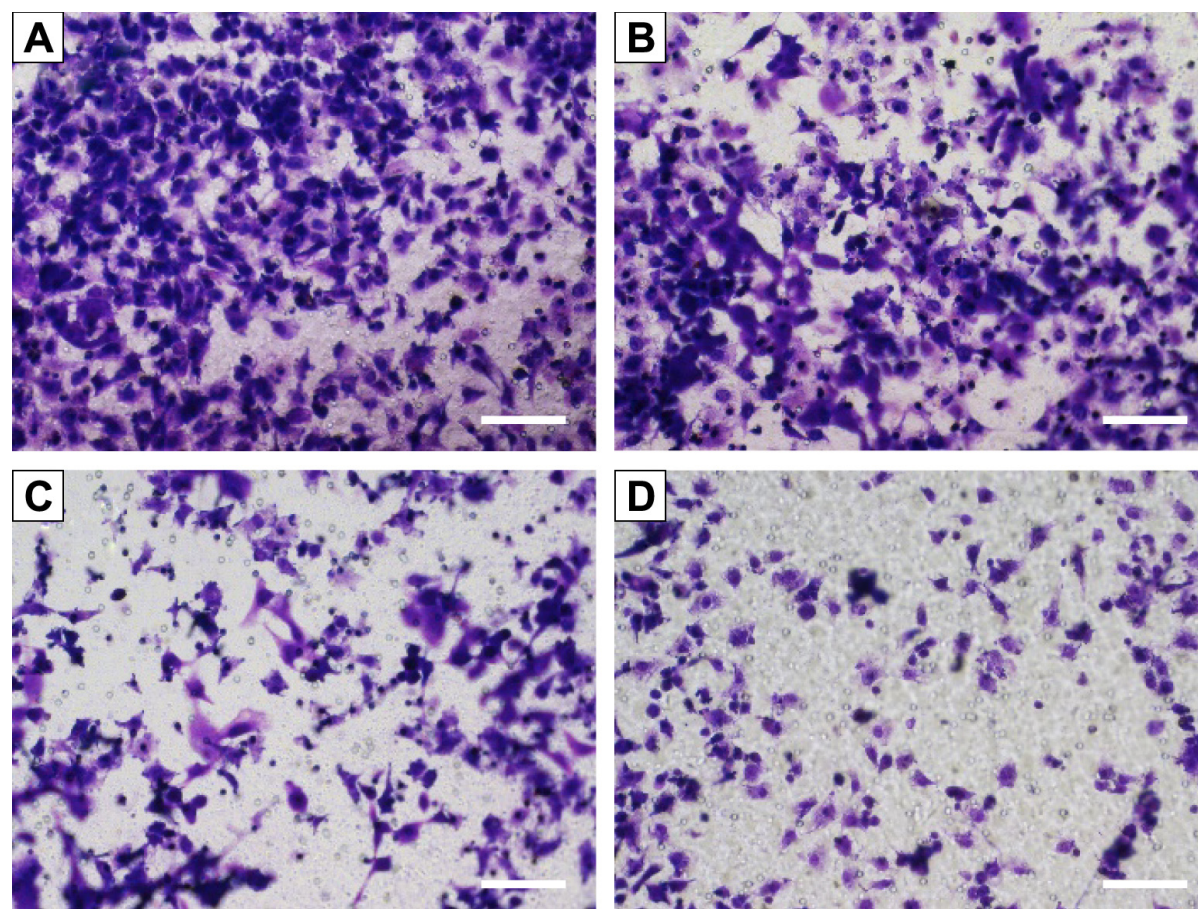

Figure 10 Transwell migration assay of HeLa cells after p53 transfection by different carriers: (A) control; (B) AP-PAMAM; (C) PAMAM/p53; and (D) AP-PAMAM/P53. Note: The scale bar is $100 \mu \mathrm{m}$.

Abbreviations: AP-PAMAM, 2-amino-6-chloropurine-modified PAMAM; PAMAM, polyamidoamine. 
promising therapeutic gene carrier for treating cancers and other malignant diseases.

\section{Acknowledgments}

The authors gratefully acknowledge the financial supports from Natural Science Foundation of China (nos 81373344, 81473142, and 81673502), Province-University Cooperation Project of Jilin Province (SXGJQY2017-4), and Graduate Innovation Program of Jilin University (2016149 and 2017058).

\section{Disclosure}

The authors report no conflicts of interest in this work.

\section{References}

1. Bakhtiar A, Sayyad M, Rosli R, Maruyama A, Chowdhury EH. Intracellular delivery of potential therapeutic genes: prospects in cancer gene therapy. Curr Gene Ther. 2014;14(4):247-257.

2. Joerger AC, Fersht AR. The 553 pathway: origins, inactivation in cancer, and emerging therapeutic approaches. Annu Rev Biochem. 2016;85:375-404.

3. Yue X, Zhao Y, Xu Y, Zheng M, Feng Z, Hu W. Mutant p53 in cancer: accumulation, gain-of-function, and therapy. J Mol Biol.2017;429(11): 1595-1606.

4. Mantovani F, Walerych D, Sal GD. Targeting mutant $\mathrm{p} 53$ in cancer: a long road to precision therapy. FEBS J. 2017;284(6):837-850.

5. Freed-Pastor WA, Prives C. Mutant p53: one name, many proteins. Genes Dev. 2012;26(12):1268-1286.

6. Muller PA, Vousden KH. Mutant p53 in cancer: new functions and therapeutic opportunities. Cancer Cell. 2014;25(3):304-317.

7. Karmakar A, Bratton SM, Dervishi E, et al. Ethylenediamine functionalized-single-walled nanotube (f-SWNT)-assisted in vitro delivery of the oncogene suppressor $\mathrm{p} 53$ gene to breast cancer MCF-7 cells. Int $J$ Nanomedicine. 2011;6:1045-1055.

8. Li Z, Zhang L, Li Q. Induction of apoptosis in cancer cells through $\mathrm{N}$-acetyl-1-leucine-modified polyethylenimine-mediated p53 gene delivery. Colloids Surf B Interfaces. 2015;135:630-638.

9. Zhang J, Wu D, Xing Z, et al. $N$-Isopropylacrylamide-modified polyethylenimine-mediated $\mathrm{p} 53$ gene delivery to prevent the proliferation of cancer cells. Colloids Surf B Interfaces. 2015;129:54-62.

10. Cai X, Jin R, Wang J, et al. Bioreducible fluorinated peptide dendrimers capable of circumventing various physiological barriers for highly efficient and safe gene delivery. ACS Appl Mater Interfaces. 2016;8(9): 5821-5832.

11. Chen S, Rong L, Lei Q, et al. A surface charge-switchable and folate modified system for codelivery of proapoptosis peptide and $\mathrm{p} 53$ plasmid in cancer therapy. Biomaterials. 2016;77:149-163.

12. Davoodi P, Srinivasan MP, Wang CH. Synthesis of intracellular reduction-sensitive amphiphilic polyethyleneimine and poly( $\varepsilon$-caprolactone) graft copolymer for on-demand release of doxorubicin and $\mathrm{p} 53$ plasmid DNA. Acta Biomater. 2016;39:79-93.

13. Duan S, Yu B, Gao C, Yuan W, Ma J, Xu FJ. A facile strategy to prepare hyperbranched hydroxyl-rich polycations for effective gene therapy. ACS Appl Mater Interfaces. 2016;8(43):29334-29342.

14. Meng T, Wu J, Yi H, et al. A spermine conjugated stearic acid-gchitosan oligosaccharide polymer with different types of amino groups for efficient p53 gene therapy. Colloids Surf B Interfaces. 2016;145: 695-705.
15. Yin H, Kanasty RL, Eltoukhy AA, Vegas AJ, Dorkin JR, Anderson DG. Non-viral vectors for gene-based therapy. Nat Rev Genet. 2014;15(8): 541-555.

16. Gillies ER, Frechet JMJ. Dendrimers and dendritic polymers in drug delivery. Drug Discov Today. 2005;10(1):35-43.

17. Lee CC, MacKay JA, Fréchet JM, Szoka FC. Designing dendrimers for biological applications. Nat Biotechnol. 2005;23(12):1517-1526.

18. Tomalia DA. Birth of a new macromolecular architecture: dendrimers as quantized building blocks for nanoscale synthetic polymer chemistry. Prog Polym Sci. 2005;30:294-324.

19. Yin Z, Liu N, Ma M, Wang L, Hao Y, Zhang X. A novel EGFR-targeted gene delivery system based on complexes self-assembled by EGF, DNA, and activated PAMAM dendrimers. Int J Nanomedicine. 2012;7: 4625-4635.

20. Labieniec-Watala M, Watala C. PAMAM dendrimers: destined for success or doomed to fail? Plain and modified PAMAM dendrimers in the context of biomedical applications. J Pharm Sci. 2015;104(1):2-14.

21. Matai I, Sachdev A, Gopinath P. Self-assembled hybrids of fluorescent carbon dots and PAMAM dendrimers for epirubicin delivery and intracellular imaging. ACS Appl Mater Interfaces. 2015;7(21):11423-11435.

22. Wang F, Wang Y, Wang H, Shao N, Chen Y, Cheng Y. Synergistic effect of amino acids modified on dendrimer surface in gene delivery. Biomaterials. 2014;35(33):9187-9198.

23. Wang F, Hu K, Cheng Y. Structure-activity relationship of dendrimers engineered with twenty common amino acids in gene delivery. Acta Biomater. 2016;29:94-102.

24. Fu F, Wu Y, Zhu J, Wen S, Shen M, Shi X. Multifunctional lactobionic acid-modified dendrimers for targeted drug delivery to liver cancer cells: investigating the role played by PEG spacer. ACS Appl Mater Interfaces. 2014;6(18):16416-16425.

25. Wang Y, Li L, Shao N, et al. Triazine-modified dendrimer for efficient TRAIL gene therapy in osteosarcoma. Acta Biomater. 2015;17: $115-124$.

26. Chen W, Liu Y, Liang X, Huang Y, Li Q. Chondroitin sulfate-functionalized polyamidoamine as a tumor-targeted carrier for miR-34a delivery. Acta Biomater. 2017;57:238-250.

27. Wang M, Liu H, Li L, Cheng Y. A fluorinated dendrimer achieves excellent gene transfection efficacy at extremely low nitrogen to phosphorus ratios. Nat Commun. 2014;5:3053.

28. Wang M, Cheng Y. The effect of fluorination on the transfection efficacy of surface-engineered dendrimers. Biomaterials. 2014;35(24): 6603-6613.

29. Shao N, Dai T, Liu Y, Cheng Y. A supramolecular approach to improve the gene transfection efficacy of dendrimers. Chem Commun. 2015; 51(47):9741-9743.

30. Wang H, Wei H, Huang Q, et al. Nucleobase-modified dendrimers as nonviral vectors for efficient and low cytotoxic gene delivery. Colloids Surf B Biointerfaces. 2015;136:1148-1155.

31. Han H, Yang J, Wang Y, et al. Nucleobase-modified polyamidoaminemediated miR-23b delivery to inhibit the proliferation and migration of lung cancer. Biomater Sci. 2017;5(11):2268-2275.

32. Wu D, Wang C, Yang J, et al. Improving the intracellular drug concentration in lung cancer treatment through the codelivery of doxorubicin and miR-519c mediated by porous PLGA microparticle. Mol Pharm. 2016;13(11):3925-3933.

33. Julien O, Wells JA. Caspases and their substrates. Cell Death Differ. 2017;24(8):1380-1389. 


\section{Supplementary materials}
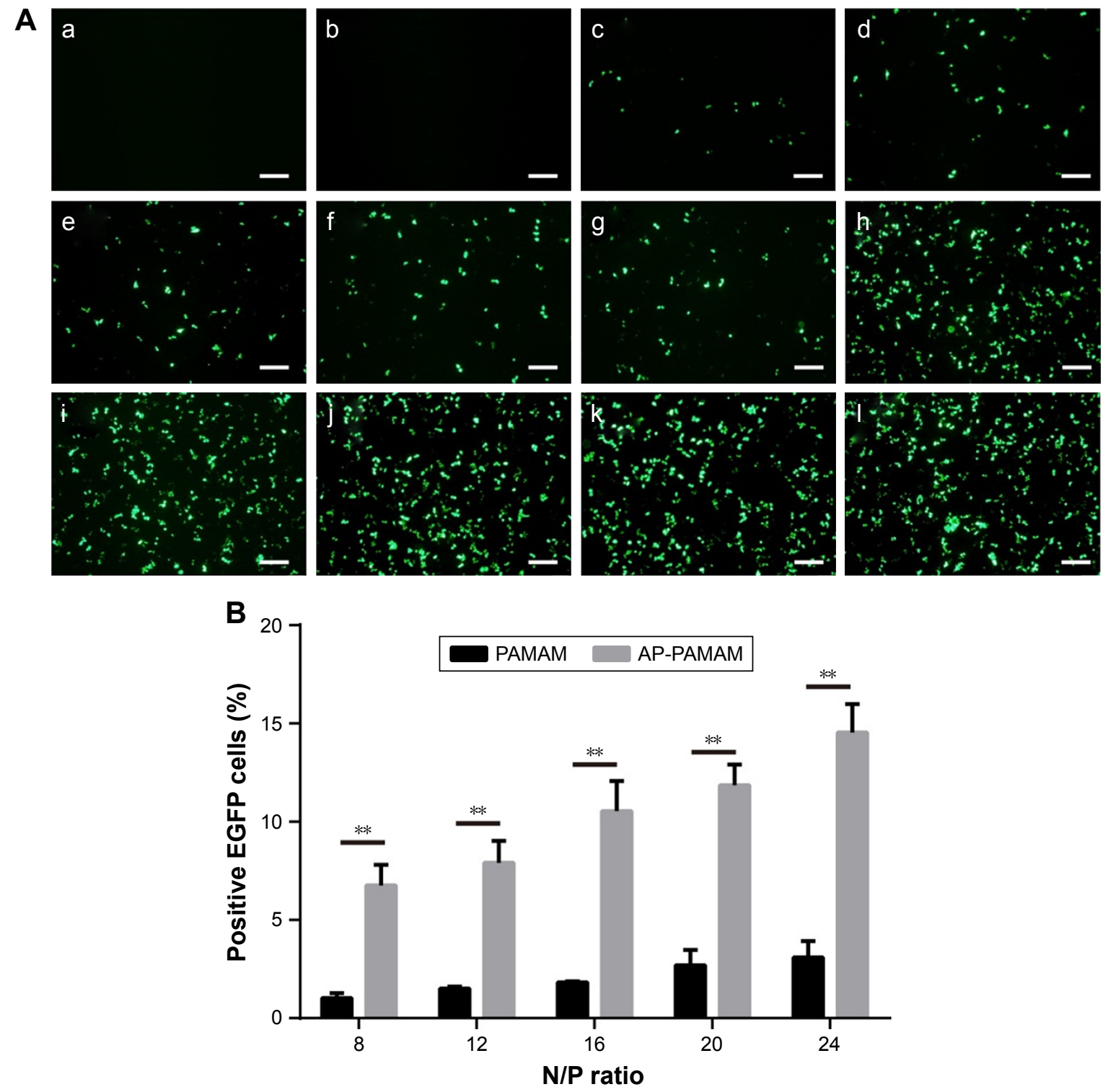

Figure SI The in vitro transfection efficiency (A) and the quantitative assay through flow cytometry (B) using pEGFP-N3 in HeLa cells as a model: (a) control; (b) free PEGFP-N3; (c-g) PAMAM/pEGFP-N3 transfection at N/P ratios of 8, 12, 16, 20, and 24, respectively; and (h-I) AP-PAMAM/pEGFP-N3 transfection at N/P ratios of 8, I2, 16,20 , and 24, respectively.

Notes: The scale bar is $400 \mu \mathrm{m} . * * P<0.01$.

Abbreviations: AP-PAMAM, 2-amino-6-chloropurine-modified PAMAM; PAMAM, polyamidoamine. 


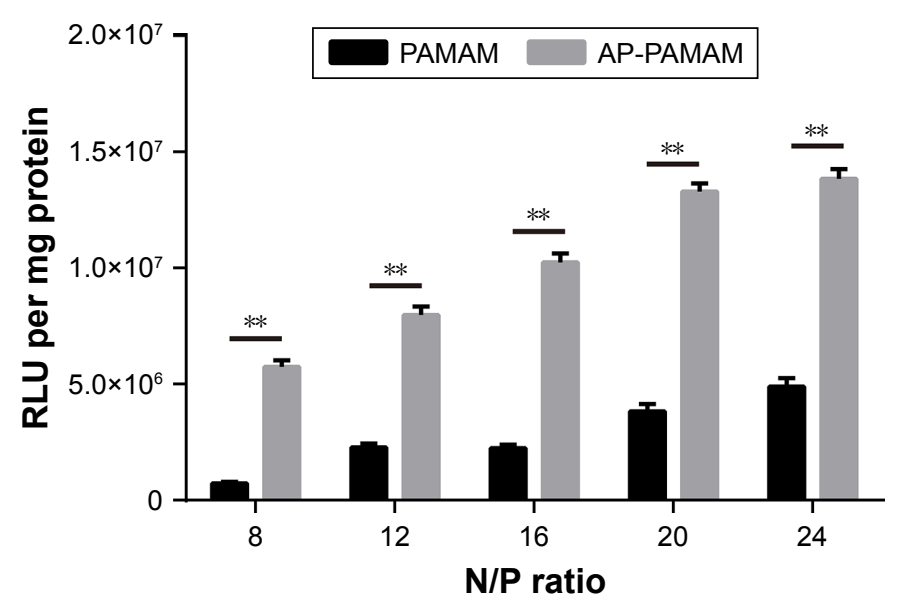

Figure S2 The quantitative assay of in vitro transfection efficiency of PAMAM and AP-PAMAM at different N/P ratios, using the transfection of pGL-3 in HeLa cells as a model.

Note: $* * P<0.01$.

Abbreviations: AP-PAMAM, 2-amino-6-chloropurine-modified PAMAM; PAMAM, polyamidoamine.

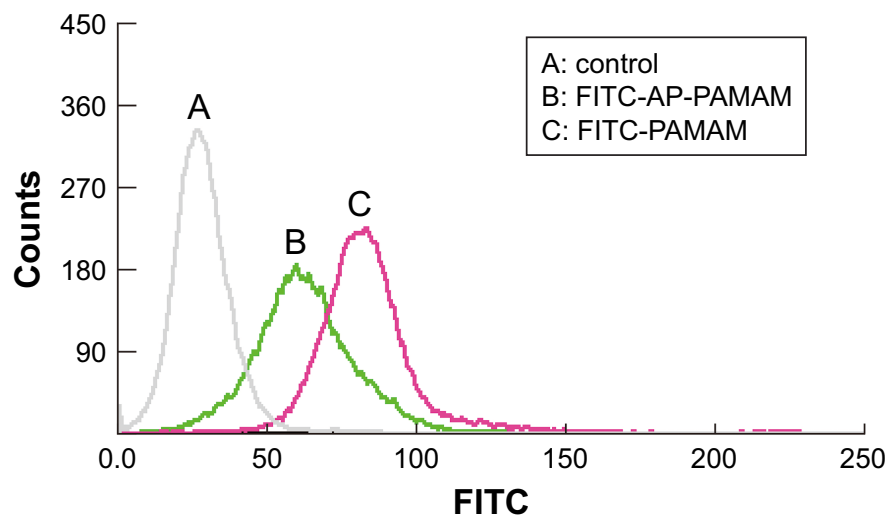

Figure S3 Flow cytometric analysis of the endocytosis of FITC-labeled PAMAM or AP-PAMAM after $2 \mathrm{~h}$.

Abbreviations: AP-PAMAM, 2-amino-6-chloropurine-modified PAMAM; FITC, fluoresceine isothiocyanate; PAMAM, polyamidoamine.
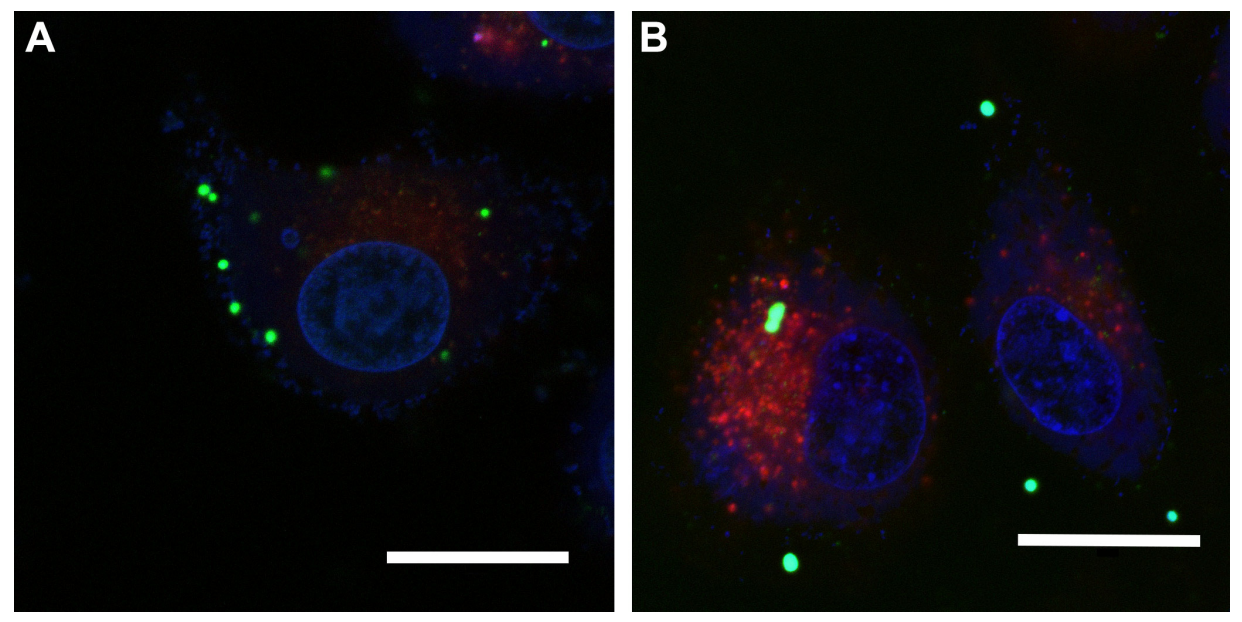

Figure S4 The confocal laser scanning microscope images of the intracellular distribution of FITC-labeled AP-PAMAM (A) and PAMAM (B) after 4 h. Notes: Blue, nuclei (DAPI); red, lysosome (Lyso-Tracker Red); green, carrier (FITC labeled). The scale bar is $20 \mu \mathrm{m}$.

Abbreviations: AP-PAMAM, 2-amino-6-chloropurine-modified PAMAM; DAPI, 4,6-diamidino-2-phenylindole; PAMAM, polyamidoamine. 


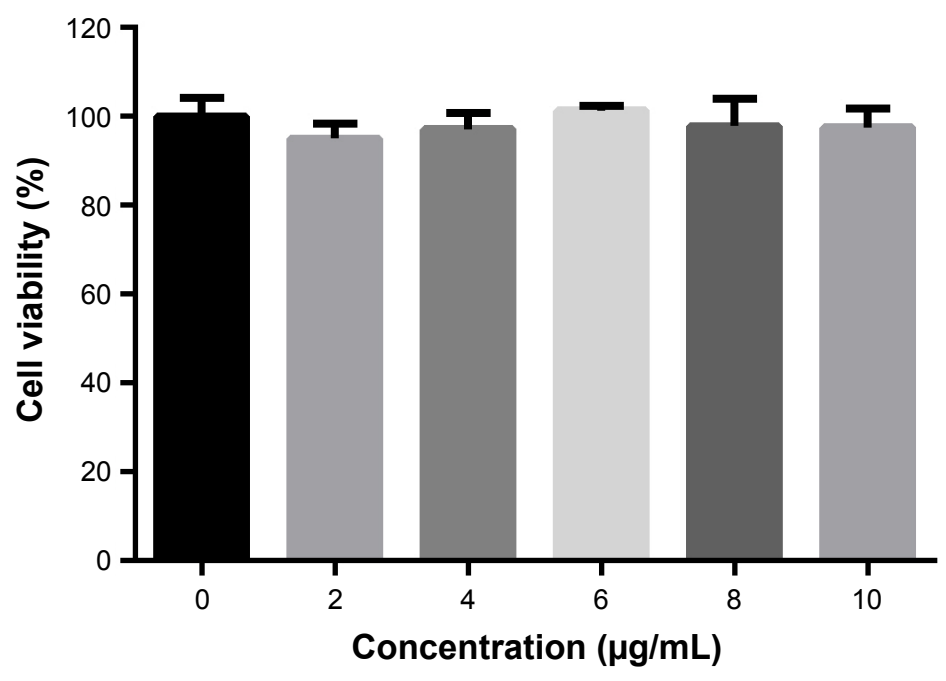

Figure S5 Cytotoxicity analysis of free nucleobase 2-amino-6-chloropurine using HeLa cell as a model. Note: Data are expressed as mean \pm SD of three experiments.

Table SI Hydrodynamic diameter and zeta potential of AP-PAMAM/p53 nanoparticles at different N/P ratios

\begin{tabular}{llll}
\hline Nanoparticle & N/P ratio & $\begin{array}{l}\text { Hydrodynamic } \\
\text { diameter }(\mathbf{n m})\end{array}$ & $\begin{array}{l}\text { Zeta potential } \\
(\mathbf{m V})\end{array}$ \\
\hline AP-PAMAM & & $809.2 \pm 18.9$ & $30.1 \pm 2.2$ \\
PAMAM & & $686.2 \pm 22.1$ & $44.4 \pm 1.8$ \\
AP-PAMAM/P53 & 15 & $125.6 \pm 10.4$ & $10.9 \pm 0.8$ \\
& 25 & $143.2 \pm 4.5$ & $15.8 \pm 3.2$ \\
& 30 & $108.9 \pm 3.5$ & $17.5 \pm 2.3$ \\
& 40 & $141.8 \pm 2.9$ & $24.1 \pm 1.4$ \\
\hline
\end{tabular}

Note: Data are expressed as mean \pm SD of three experiments.

Abbreviations: AP-PAMAM, 2-amino-6-chloropurine-modified PAMAM; PAMAM, polyamidoamine.
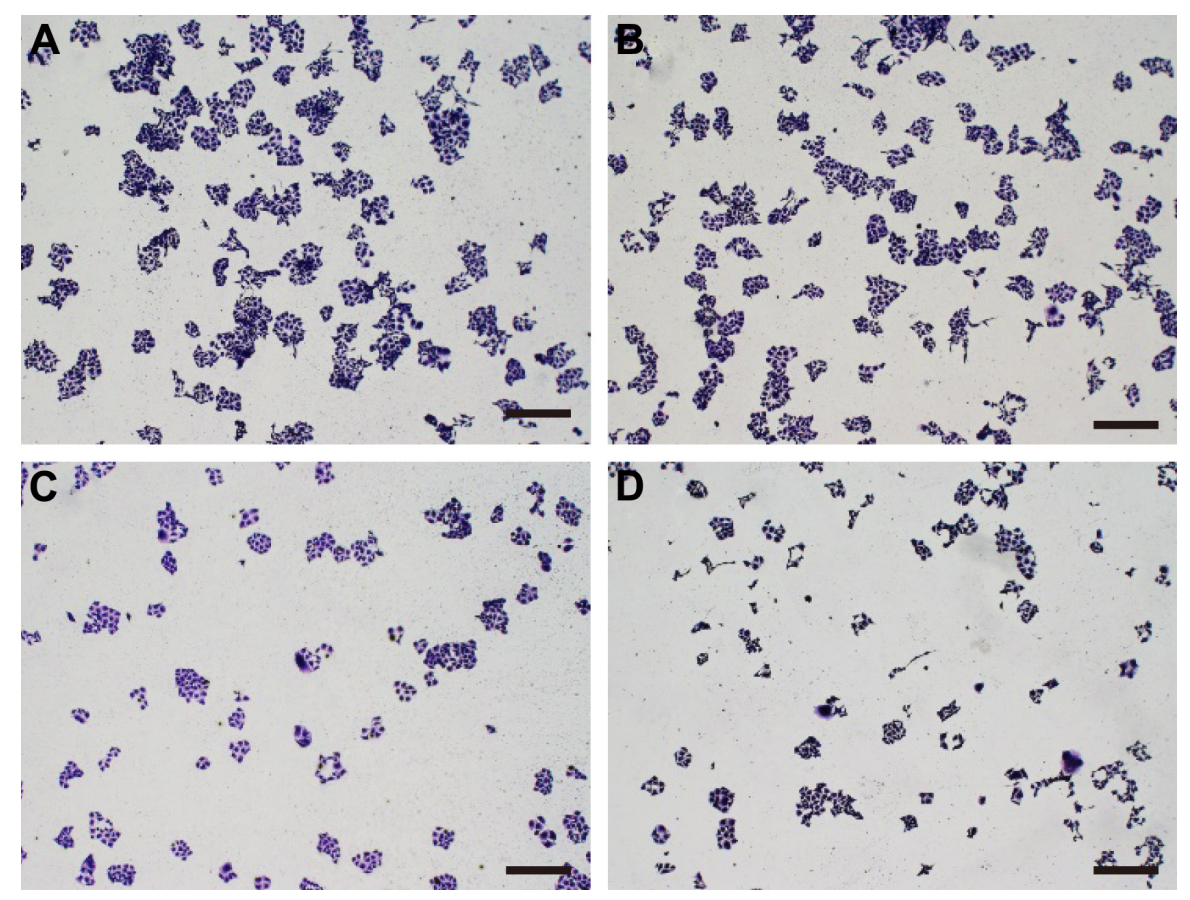

Figure S6 Inhibition of the formation of cell colony by p53 transfection mediated by different carriers: (A) control; (B) AP-PAMAM; (C) PAMAM/p53; and (D) AP-PAMAM/P53. Note: The scale bar is $400 \mu \mathrm{m}$.

Abbreviations: AP-PAMAM, 2-amino-6-chloropurine-modified PAMAM; PAMAM, polyamidoamine. 

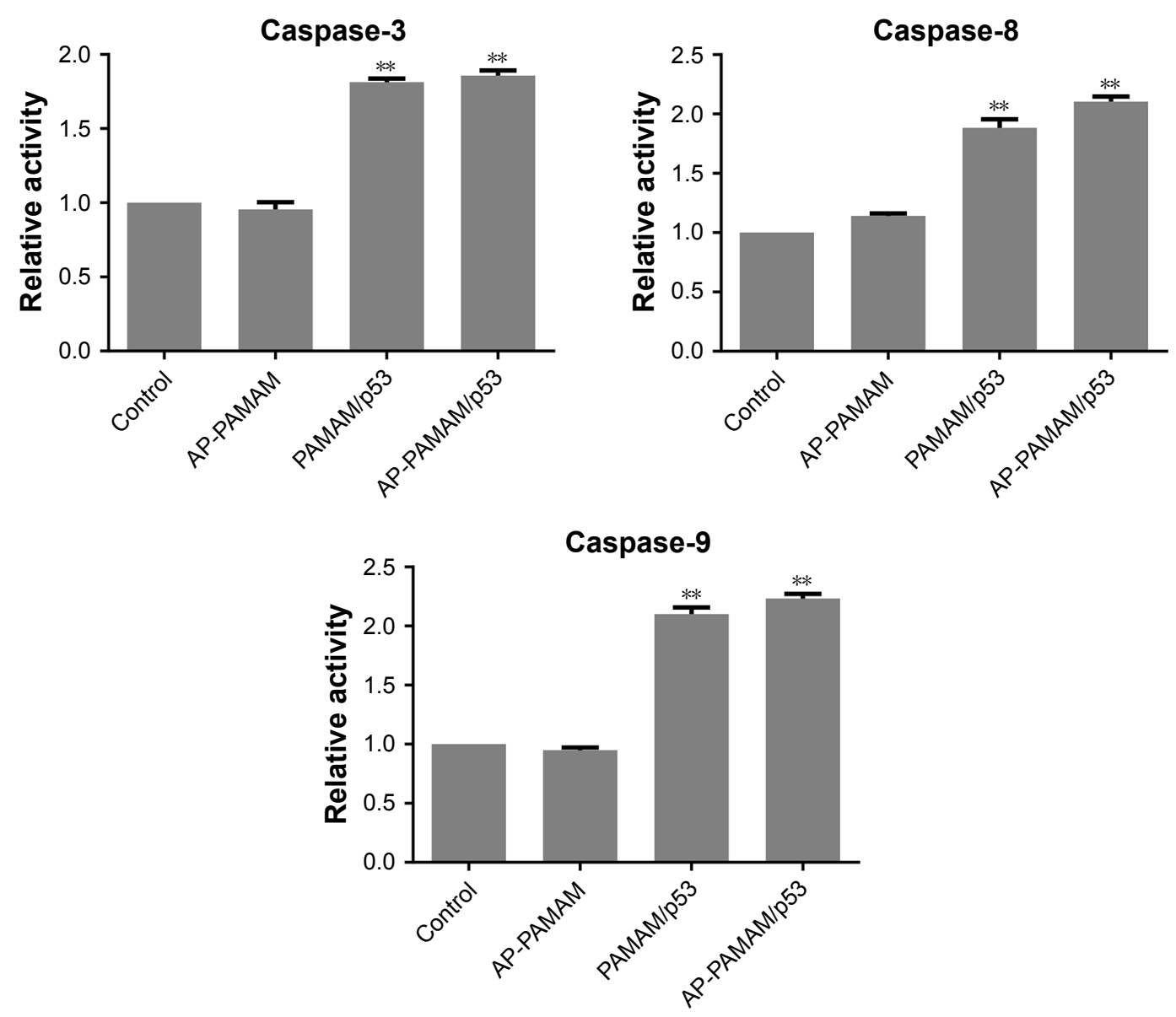

Figure S7 Relative activities of caspase-3, -8 , and -9 after $p 53$ transfection mediated by different carriers.

Note: $* * P<0.01$.

Abbreviations: AP-PAMAM, 2-amino-6-chloropurine-modified PAMAM; PAMAM, polyamidoamine.

International Journal of Nanomedicine

\section{Publish your work in this journal}

The International Journal of Nanomedicine is an international, peerreviewed journal focusing on the application of nanotechnology in diagnostics, therapeutics, and drug delivery systems throughou the biomedical field. This journal is indexed on PubMed Central, MedLine, CAS, SciSearch $®$, Current Contents $\AA /$ Clinical Medicine,
Journal Citation Reports/Science Edition, EMBase, Scopus and the Elsevier Bibliographic databases. The manuscript management system is completely online and includes a very quick and fair peer-review system, which is all easy to use. Visit http://www.dovepress.com/ testimonials.php to read real quotes from published authors. 